\title{
Differences in Urinary Renal Failure Biomarkers in Cancer Patients Initially Treated with Cisplatin
}

\author{
AKIMITSU MAEDA ${ }^{1,2}$, HITOSHI ANDO ${ }^{2}$, TAKASHI URA ${ }^{3}$, KEI MURO ${ }^{3}$, MASAHIRO AOKI $^{4}$, KEN SAITO $^{5}$, \\ EISAKU KONDO ${ }^{5}$, SHINJI TAKAHASHI ${ }^{1}$, YUKO ITO $^{1}$, YASUNARI MIZUNO $^{1}$ and AKIO FUJIMURA ${ }^{2}$ \\ ${ }^{1}$ Department of Pharmacy, Aichi Cancer Center Hospital, Nagoya, Japan; \\ ${ }^{2}$ Division of Clinical Pharmacology, Department of Pharmacology, Jichi Medical University, Tochigi, Japan; \\ ${ }^{3}$ Department of Clinical Oncology, Aichi Cancer Center Hospital, Nagoya, Japan; \\ ${ }^{4}$ Division of Molecular Pathology, Aichi Cancer Center Research Institute, Nagoya, Japan; \\ ${ }^{5}$ Division of Molecular and Cellular Pathology, \\ Niigata University Graduate School of Medical and Dental Sciences, Niigata, Japan
}

\begin{abstract}
Background/Aim: We investigated whether measuring the excretion of each acute kidney injury (AKI) biomarker after cisplatin (CDDP) administration is useful for predicting AKI and evaluated the most appropriate AKI marker in patients treated with CDDP. Patients and Methods: We measured NAG, Kim-1, and NGAL in urinary samples of 40 cancer patients treated with chemotherapy on day 1 (before chemotherapy), day 2, and day 5 after treatment; serum creatinine ( $\mathrm{sCr}$ ) was compared on days 7 and 28 after CDDP administration vs. baseline. Results: NAG, Kim-1, and NGAL excretion (creatinine corrected) were not significantly elevated 5 days after receiving chemotherapy in the non-CDDP chemotherapy group. Conversely, all markers were significantly higher 5 days after receiving chemotherapy in the CDDP group when compared to baseline. Conclusion: Urinary NAG, Kim-1, and NGAL can detect renal injury more sensitively than $\mathrm{sCr}$.

Cisplatin (CDDP) is an antineoplastic agent that has been shown to provide survival benefits in patients with various types of cancer $(1,2)$. However, this compound has been shown to induce kidney injury (3). Therefore, early diagnosis of acute kidney injury (AKI) in patients receiving CDDP is important to lower the risk of severe renal failure. Common predictors of kidney injury are serum creatinine $(\mathrm{sCr})$ and
\end{abstract}

Correspondence to: Akimitsu Maeda, Department of Pharmacy, Aichi Cancer Center Hospital, 1-1 Kanokoden, Chikusa-ku, Nagoya, Aichi 464-8681, Japan. Tel: +81 527626111, Fax: +81 527642949, e-mail: m.akimitsu@aichi-cc.jp

Key Words: $N$-acetyl- $\beta$-D-glucosaminidase, kidney injury molecule1 , neutrophil gelatinase-associated lipocalin, cisplatin, acute kidney injury. glomerular filtration rate (GFR) measured via urine analysis. However, these biomarkers are not sensitive nor specific enough to predict AKI in the early stages of renal failure (4). Treatment by CDDP tends to be administered over long-term hospitalization; however, recently, this chemotherapy has been administered over short-term hospitalization or in ambulatory care facilities because of developments in antiemetic drugs (5). Hence, if early discrimination of the risk of acute renal failure is made possible, there can be earlier detection and treatment of AKI supported by longterm monitoring of renal status.

Kidney injury by CDDP is caused by renal tubular damage $(6,7)$, and a previous study showed that some enzymes excreted in the urine can predict renal tubular damage (8). One of these enzymes is $N$-acetyl- $\beta$-Dglucosaminidase (NAG), that is a lysosomal enzyme that is abundant in the cells of the proximal kidney tubule, and is excreted in the urine at the time of cell damage (9). NAG has been shown in previous studies to be increased in the early stages of AKI (9-11). However, endogenous urea can reportedly decrease the activity of this enzyme (12). Furthermore, its levels can increase as a result of diseases other than AKI such as rheumatoid arthritis and abnormal glucose tolerance, and its specificity to AKI is low $(13,14)$. Here, an excellent AKI biomarker may detect AKI earlier than $\mathrm{SCr}$ and GFR fluctuations would; further, this detection would not be influenced by diseases other than AKI.

Kidney injury molecule-1 (Kim-1) and neutrophil gelatinase-associated lipocalin (NGAL) may be effective for the early diagnosis of AKI in patients receiving CDDP (8, 15). However, Kim-1 is known to increase in pre-renal AKI with accompanying dehydration, and it has an unsuitable profile in hydration therapy during the course of CDDP treatment (8). On the other hand, NGAL has little fluctuation in pre-renal AKI, and may be effective in the evaluation of 
Table I. Comparison of the characteristics of patients in the CDDP and non-CDDP chemotherapy groups.

\begin{tabular}{|c|c|c|c|c|}
\hline $\mathrm{N}=40$ & $\begin{array}{l}\mathrm{CDDP}(+) \\
\mathrm{N}=27\end{array}$ & $\begin{array}{l}\operatorname{CDDP}(-) \\
\mathrm{N}=13\end{array}$ & $p$-Value & $\begin{array}{c}\text { Healthy volunteer } \\
\qquad \mathrm{N}=6\end{array}$ \\
\hline \multicolumn{5}{|l|}{ Cancer diagnosis } \\
\hline Esophagus & 16 & 0 & & \\
\hline Stomach & 7 & 0 & & \\
\hline Lung & 4 & 2 & & \\
\hline Colon & 0 & 8 & & \\
\hline Soft tissue tumor & 0 & 2 & & \\
\hline Anal canal & 0 & 1 & & \\
\hline CDDP dose $\left(\mathrm{mg} / \mathrm{m}^{2}\right)$ & $69 \pm 7.8$ & 0 & & \\
\hline Age (years) & $63.8 \pm 8.6$ & $63.1 \pm 10.9$ & 0.83 & $54.3 \pm 4.6$ \\
\hline Male $(\mathrm{n}, \%)$ & $21(78)$ & $7(54)$ & 0.12 & $3(50)$ \\
\hline $\operatorname{BSA}\left(/ \mathrm{m}^{2}\right)$ & $1.6 \pm 0.2$ & $1.6 \pm 0.16$ & 0.70 & $1.6 \pm 0.17$ \\
\hline Diabetes $(\mathrm{n}, \%)$ & $3(11)$ & $0(0)$ & 0.21 & $0(0)$ \\
\hline Hypertension $(\mathrm{n}, \%)$ & $7(26)$ & $5(38)$ & 0.42 & $1(17)$ \\
\hline Serum Cr (mg/dl) & $0.71 \pm 0.16$ & $0.70 \pm 0.22$ & 0.95 & $0.74 \pm 0.18$ \\
\hline $\mathrm{eCCr}(\mathrm{mL} / \mathrm{min})$ & $83.0 \pm 24$ & $84.5 \pm 25$ & 0.85 & $91.1 \pm 25$ \\
\hline NAG (U/L) & $8.84 \pm 10.2$ & $12.9 \pm 21.0$ & 0.41 & $1.82 \pm 1.1$ \\
\hline $\mathrm{NAG} / \mathrm{Cr}(\mathrm{U} / \mathrm{g} \mathrm{Cr})$ & $6.60 \pm 4.4$ & $11.1 \pm 14.2$ & 0.14 & $2.75 \pm 0.9$ \\
\hline Kim-1 (ng/ml) & $1.41 \pm 1.1$ & $1.71 \pm 2.3$ & 0.58 & $0.40 \pm 0.3$ \\
\hline $\mathrm{Kim}-1 / \mathrm{Cr}(\mathrm{ng} / \mathrm{mg} \mathrm{Cr})$ & $1.62 \pm 2.0$ & $1.48 \pm 1.0$ & 0.81 & $0.54 \pm 0.4$ \\
\hline $\operatorname{NGAL}(\mathrm{ng} / \mathrm{ml})$ & $8.79 \pm 7.2$ & $13.0 \pm 14.4$ & 0.22 & $5.11 \pm 4.5$ \\
\hline $\mathrm{NGAL} / \mathrm{Cr}(\mathrm{ng} / \mathrm{mg} \mathrm{Cr})$ & $8.93 \pm 6.2$ & $13.0 \pm 9.4$ & 0.12 & $6.93 \pm 5.2$ \\
\hline
\end{tabular}

Data are presented as means \pm standard deviations (S.D.). BSA: Body surface area; eCCr: estimated creatinine clearance (Cockcroft-Gault); NAG: $N$-acetyl- $\beta$-D-glucosaminidase; NGAL: neutrophil gelatinase-associated lipocalin; Kim-1: kidney injury molecule-1; Cr: creatinine.

acute renal injury after CDDP therapy (16). However, only a few subjects of studies have assessed the fluctuation of NGAL after CDDP administration, and there is insufficient data on this topic. In addition, few reports have directly compared the levels of novel markers such as Kim-1 and NGAL in patients treated with CDDP, and measurement of the fluctuations of each tubule biomarker in these patients may be useful in biomarker research. We investigated the existence of fluctuations in NAG, Kim-1, and NGAL caused by cancer, as well as variations in these biomarkers after CDDP administration to clarify the most appropriate AKI marker in patients treated with CDDP.

\section{Patients and Methods}

Patients. This study was a prospective, observational study conducted at Aichi Cancer Center Hospital, Nagoya, Japan, from October 2012 to August 2013. Patients were recruited based on the following inclusion criteria: (1) at least 20 years old and (2) naive to treatment with CDDP. Patients who were initially administered anti-cancer drugs other than CDDP and healthy volunteers were enrolled as controls. The exclusion criteria included patients with an estimated creatinine $(\mathrm{Cr})$ clearance of less than $50 \mathrm{ml} / \mathrm{min}$ as calculated by the Cockcroft-Gault formula. All patients were of Japanese descent and provided written informed consent. This study was approved by the ethics committee of Aichi Cancer Center Hospital, and was conducted in accordance with the declaration of Helsinki.
Methods and measurements. We collected midstream urinary samples on waking up in the morning from all participants before the administration of chemotherapy (day 1) and on days 2 and 5 after treatment. Furthermore, blood specimens were collected the day before starting chemotherapy and on days 7 (6-8) and 28 (2135) after treatment of $\mathrm{sCr}$ measurement. Blood specimens and urinary samples were collected at one point from healthy volunteers. We also measured NAG, NGAL, and Kim-1 in the urine specimens. Urine $\mathrm{Cr}$ was measured for correcting each tubule biomarker concentration.

NGAL and Kim-1 concentrations were measured by enzymelinked immunosorbent assay according to the manufacturer's instructions (R\&D Systems, Inc. Minneapolis, MN, USA). NAG and $\mathrm{Cr}$ were measured using a colorimetric method and enzyme assay (SRL, Inc. Tokyo, Japan).

Statistical analysis. The characteristic data were analyzed using Student's $t$-test and the Mann-Whitney $U$-test. Differences in data were analyzed using one-way analysis of variance followed by Dunnett's test. $p$-Values $<0.05$ were considered statistically significant. All calculations were performed using EZR version 1.27 (17).

\section{Results}

The characteristics of the 46 subjects enrolled in this study are summarized in Table I. Twenty-seven patients received CDDP. The majority of patients had esophageal cancer $(\mathrm{n}=16,60 \%)$, and followed a 5-fluorouracil-based regimen 
Table II. Comparison of baseline characteristics for all cancer patients included in this study.

\begin{tabular}{|c|c|c|c|c|c|c|c|c|}
\hline & \multirow[b]{2}{*}{ Healthy volunteer } & \multicolumn{6}{|c|}{ Cancer patients } & \multirow[b]{2}{*}{ All } \\
\hline & & Esophagus & Stomach & Colon & Lung & Soft tissue tumor & Anal canal & \\
\hline $\mathrm{n}$ & 6 & 16 & 7 & 8 & 6 & 2 & 1 & 40 \\
\hline Age (years) & $54.3 \pm 4.6$ & $65.3 \pm 6.4^{*}$ & $61.6 \pm 12$ & $64.8 \pm 9.4$ & $62.8 \pm 8.1$ & $52 \pm 22$ & 66 & $63.6 \pm 1.5^{*}$ \\
\hline Male (n, \%) & $3(50)$ & $14(88)$ & $3(43)$ & $3(38)$ & $6(100)$ & $1(50)$ & 1 & $28(70)$ \\
\hline $\operatorname{BSA}\left(/ \mathrm{m}^{2}\right)$ & $1.6 \pm 0.17$ & $1.7 \pm 0.17$ & $1.6 \pm 0.18$ & $1.6 \pm 0.16$ & $1.7 \pm 0.13$ & & & $1.6 \pm 0.17$ \\
\hline Diabetes (n, \%) & $0(0)$ & $2(13)$ & $1(14)$ & $0(0)$ & $0(0)$ & $0(0)$ & $0(0)$ & $3(8)$ \\
\hline Hypertension (n, \%) & $1(17)$ & $7(44)$ & $0(0)$ & $2(25)$ & $1(17)$ & $1(50)$ & $1(100)$ & $12(30)$ \\
\hline Serum Cr $(\mathrm{mg} / \mathrm{dl})$ & $0.74 \pm 0.18$ & $0.74 \pm 0.17$ & $0.63 \pm 0.13$ & $0.71 \pm 0.25$ & $0.72 \pm 0.10$ & & & $0.71 \pm 0.18$ \\
\hline $\mathrm{eCCr}(\mathrm{mL} / \mathrm{min})$ & $93.7 \pm 13$ & $79.5 \pm 20$ & $82.9 \pm 23$ & $77.7 \pm 17$ & $93.8 \pm 30$ & & & $83.5 \pm 23$ \\
\hline NAG (U/l) & $1.8 \pm 1.1$ & $6.2 \pm 4.9$ & $15.4 \pm 17$ & $9.2 \pm 13$ & $6.0 \pm 5.9$ & & & $10.2 \pm 14$ \\
\hline $\mathrm{NAG} / \mathrm{Cr}(\mathrm{U} / \mathrm{g} \mathrm{Cr})$ & $2.8 \pm 0.9$ & $6.3 \pm 4.9$ & $7.2 \pm 4.0$ & $11.5 \pm 15$ & $5.3 \pm 4.5$ & & & $8.0 \pm 9.0$ \\
\hline $\mathrm{Kim}-1(\mathrm{ng} / \mathrm{ml})$ & $0.40 \pm 0.3$ & $1.5 \pm 1.4$ & $1.6 \pm 0.9$ & $1.2 \pm 0.8$ & $0.80 \pm 0.5$ & & & $1.5 \pm 1.6$ \\
\hline $\mathrm{Kim}-1 / \mathrm{Cr}(\mathrm{ng} / \mathrm{mg} \mathrm{Cr})$ & $0.54 \pm 0.4$ & $1.4 \pm 0.6$ & $2.7 \pm 3.8$ & $1.4 \pm 0.6$ & $0.77 \pm 0.4$ & & & $15 \pm 1.7$ \\
\hline NGAL (ng/ml) & $5.1 \pm 4.5$ & $7.5 \pm 7.4$ & $11.6 \pm 4.4$ & $8.8 \pm 7.4$ & $7.6 \pm 8.7$ & & & $10.2 \pm 10$ \\
\hline NGAL/Cr (ng/mg Cr) & $6.9 \pm 5.2$ & $7.9 \pm 5.4$ & $11 \pm 4.1$ & $13 \pm 9.5$ & $8.0 \pm 9.4$ & & & $10.3 \pm 7.6$ \\
\hline
\end{tabular}

Data were analyzed statistically using one-way analysis of variance followed by the Dunnett's test. ${ }^{*} p<0.05 v s$. healthy volunteers. Data are presented as means \pm standard deviations (S.D.). BSA: Body surface area; eCCr: estimated creatinine clearance (Cockcroft-Gault); NAG: $N$-acetyl- $\beta$-Dglucosaminidase; NGAL: neutrophil gelatinase-associated lipocalin; Kim-1: kidney injury molecule-1; Cr: creatinine.

(e.g. DCF: docetaxel, CDDP, and 5-fluorouracil or FP: CDDP and 5-fluorouracil); the median CDDP dose was $69 \pm 7.8 \mathrm{mg} / \mathrm{m}^{2}$. Thirteen patients were treated with nonCDDP chemotherapy, and most had colon cancer. There was no significant difference in the age, diabetes history, hypertension history, or renal function between the two groups. In addition, when comparing the levels of each AKI biomarker before administering chemotherapy in the patients with esophageal cancer, stomach cancer, colon cancer, and lung cancer, which were many enrolled types of cancer subjects in the study, there was no significant difference in any of the markers compared to healthy volunteers (Table II).

There were no patients with stage 1 or higher AKI ( $\mathrm{sCr}$ level elevated by $\geq 1.5$ fold or $\geq 0.3 \mathrm{mg} / \mathrm{dl}$ ) as assessed by the AKI Network criteria in the CDDP group at 7 days after administration nor before the second course of chemotherapy (Figure 1). Hence, it was not possible to investigate the variations in each AKI biomarker in the presence or absence of AKI.

When comparing the CDDP and non-CDDP chemotherapy groups, no significant increase in any of these markers was observed on days 2 and 5 after treatment compared to baseline in the non-CDDP chemotherapy patients. Conversely, in the CDDP patients, although no change was observed on day 2 after treatment in the levels of any of these markers, the levels of all markers were significantly higher on day 5 than at baseline (Figure 2), despite the absence of elevation in the sCr level.

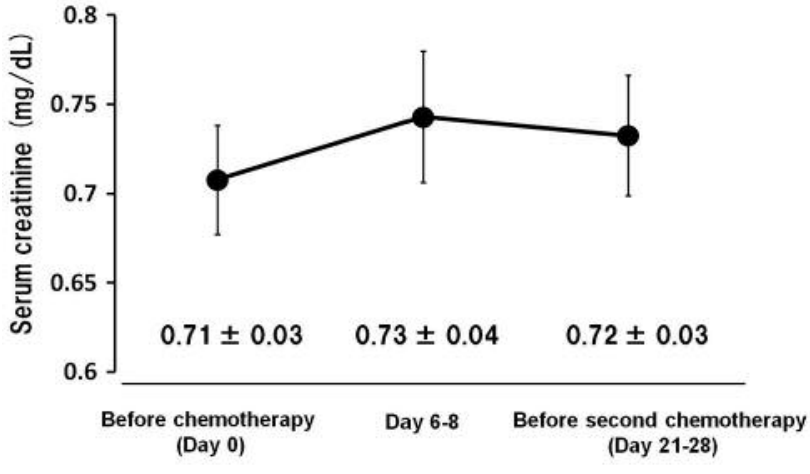

Figure 1. Time course of $\mathrm{sCr}$ levels after CDDP administration. The results of each plot are presented as the means \pm standard error (S.E.); $(n=27)$.

\section{Discussion}

The aim of the present study was to establish effective biomarkers for the early prediction of AKI caused by the disturbance of the proximal renal tubule after CDDP administration. For accurate AKI prediction, the biomarker levels should not vary with diseases other than AKI. There were no significant differences between cancer patients before the administration of anticancer drugs and the healthy controls in the values of NAG, Kim-1, or NGAL, and these markers seemed to be less likely to change in cancer patients (Table II). In this study, we aimed to compare the levels of 
A) NAG

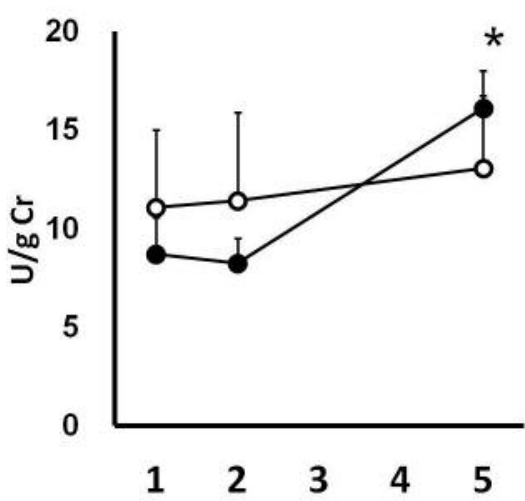

B) Kim-1

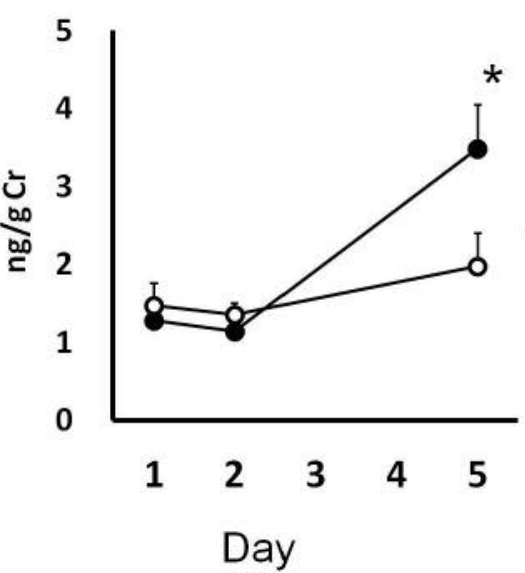

C) NGAL

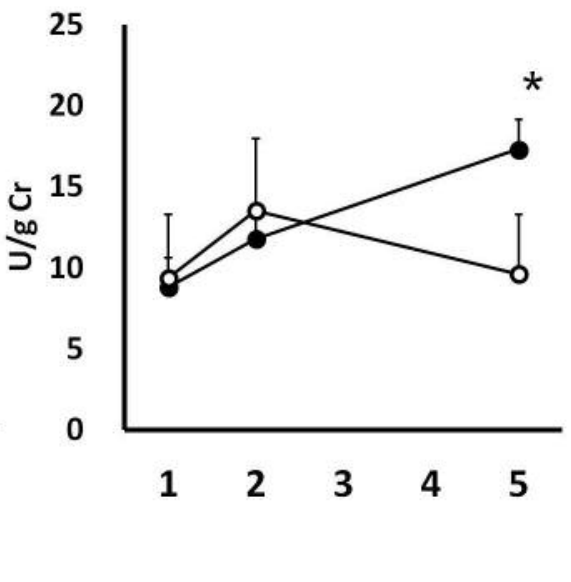

Figure 2. Time course of the urinary biomarker levels after chemotherapy. Data were analyzed statistically by one-way analysis of variance followed by the Dunnett's test. ${ }^{*} p<0.05 \mathrm{vs}$. before chemotherapy (day 1). The results of each plot are presented as the means \pm standard error (S.E.); CDDP chemotherapy group $(\bullet)$, non-CDDP chemotherapy group $(\bigcirc)$.

each biomarker between AKI cases and non-AKI cases; however, there were no AKI patients in our study groups. Therefore, we compared the levels of each biomarker between the CDDP and non-CDDP chemotherapy patients.

In a previous study, NGAL increased to more than $1,000 \%$ of the baseline value at $24 \mathrm{~h}$ after the administration of CDDP chemotherapy in AKI onset patients (18). In our study, the maximum increase of NGAL at $24 \mathrm{~h}$ after chemotherapy treatment (day 2) was $541 \%$, and the NGAL levels were not significantly higher than those previously reported in patients with AKI onset. Therefore, it seems that the prediction of AKI using urinary NGAL has good reproducibility. On the other hand, urinary Kim-1 (Kim-1/urinary $\mathrm{Cr}$ ) reportedly increased to above $1,300 \mathrm{pg} / \mathrm{mL}[500(\mathrm{pg} / \mathrm{ml}) /(\mathrm{Cr} \mathrm{mmol} / \mathrm{l})]$ at $24 \mathrm{~h}$ after the administration of CDDP chemotherapy in AKI onset patients (15). There were 10 patients in this study with Kim-1 levels higher than $1,300 \mathrm{pg} / \mathrm{ml}$, but no cases were found with Kim-1/urinary $\mathrm{Cr}$ levels more than 500 $(\mathrm{pg} / \mathrm{ml}) /(\mathrm{Cr} \mathrm{mmol} / \mathrm{l})(4.4 \mathrm{ng} / \mathrm{Cr} \mathrm{mg})$ when the levels were corrected with urine $\mathrm{Cr}$ on day 2 after treatment. Urinary Kim-1 levels are known to increase in pre-renal AKI with accompanying dehydration, and therefore, this marker is unsuitable for predicting AKI when CDDP chemotherapy is combined with a diuretic agent. However, it may be possible to solve this problem by correcting the levels with urine $\mathrm{Cr}$.

Although the incidence of renal disorder after CDDP administration has been reported to be about $10 \%$ in a previous report (19), in recent years, the incidence of acute renal disorder has decreased to $2-4.6 \%$ as a result of improvements in hydration and antiemetic therapies (20-22).
Therefore, it is necessary to conduct a larger-scale study on whether each biomarker can predict the onset of AKI and to evaluate the clinical significance of measuring each biomarker early after CDDP administration.

In the present study, the levels of NAG, Kim-1, and NGAL excretion ( $\mathrm{Cr}$ corrected) were significantly increased on day 5 after the administration of anticancer drugs compared with baseline in the CDDP group, despite the absence of $\mathrm{sCr}$ elevation. The elevation of these biomarkers is not considered to be clinically problematic; however, these biomarkers could be detected in early renal injury that could not be detected by sCr. Because these biomarkers were not increased $24 \mathrm{~h}$ after the administration of chemotherapy, it is assumed that the time course of the increase associated with renal injury is comparable.

In conclusion, our results showed that urinary NAG, Kim1 , and NGAL can detect renal injury more sensitively than $\mathrm{sCr}$. Each biomarker has similarly superior sensitivity and is elevated with similar time course; therefore, we did not find any differences in the levels of each biomarker. We believe that NAG, Kim-1, and NGAL can reflect potential renal injury following CDDP administration, and these biomarkers may be useful in the early assessment of renal injury.

\section{References}

1 Wang D and Lippard SJ: Cellular processing of platinum anticancer drugs. Nat Rev Drug Discov 4: 307-320, 2005.

2 Cohen SM and Lippard SJ: Cisplatin: from DNA damage to cancer chemotherapy. Prog Nucleic Acid Res Mol Biol 67: 93130, 2001. 
3 Arany I and Safirstein RL: Cisplatin nephrotoxicity. Semin Nephrol 23: 460-464, 2003.

4 Coca SG, Yalavarthy R, Concato J and Parikh CR: Biomarkers for the diagnosis and risk stratification of acute kidney injury: a systematic review. Kidney Int 73: 1008-1016, 2008.

5 Jordan K, Jahn F and Aapro M: Recent developments in the prevention of chemotherapy-induced nausea and vomiting (CINV): a comprehensive review. Ann Oncol 26: 1081-1090, 2015.

6 Park MS, De Leon M and Devarajan P: Cisplatin induces apoptosis in LLC-PK1 cells via activation of mitochondrial pathways. J Am Soc Nephrol 13: 858-865, 2002.

7 Shinke H, Masuda S, Togashi Y, Ikemi Y, Ozawa A, Sato T, Kim YH, Mishima M, Ichimura T, Bonventre JV and Matsubara K: Urinary kidney injury molecule-1 and monocyte chemotactic protein-1 are noninvasive biomarkers of cisplatin-induced nephrotoxicity in lung cancer patients. Cancer Chemother Pharmacol 76: 989-996, 2015.

8 Ostermann M, Philips BJ and Forni LG: Clinical review: Biomarkers of acute kidney injury: where are we now? Crit Care 16: $233,2012$.

9 Skalova S: The diagnostic role of urinary $N$-acetyl-beta-Dglucosaminidase (NAG) activity in the detection of renal tubular impairment. Acta Medica (Hradec Kralove) 48: 75-80, 2005.

10 Westhuyzen J, Endre ZH, Reece G, Reith DM, Saltissi D and Morgan TJ: Measurement of tubular enzymuria facilitates early detection of acute renal impairment in the intensive care unit Nephrol Dial Transplant 18: 543-551, 2003.

11 Goren MP, Wright RK and Horowitz ME: Cumulative renal tubular damage associated with cisplatin nephrotoxicity. Cancer Chemother Pharmacol 18: 69-73, 1986.

12 Bondiou MT, Bourbouze R, Bernard M, Percheron F, PerezGonzalez $\mathrm{N}$ and Cabezas JA: Inhibition of A and B $\mathrm{N}$-acetylbeta-D-glucosaminidase urinary isoenzymes by urea. Clin Chim Acta 149: 67-73, 1985.

13 Iqbal MP, Ali AA, Waqar MA and Mehboobali N: Urinary $N$ acetyl-beta-D-glucosaminidase in rheumatoid arthritis. Exp Mol Med 30: 165-169, 1998.

14 Fujita H, Narita T, Morii T, Shimotomai T, Yoshioka N, Kakei M and Ito $\mathrm{S}$ : Increased urinary excretion of $\mathrm{N}$-acetylgluco-saminidase in subjects with impaired glucose tolerance. Ren Fail 24: 69-75, 2002.

15 Tekce BK, Uyeturk U, Tekce H, Uyeturk U, Aktas G and Akkaya A: Does the kidney injury molecule-1 predict cisplatin-induced kidney injury in early stage? Ann Clin Biochem 52: 88-94, 2015.
16 Peres LA, da Cunha AD, Jr., Assumpcao RA, Schafer A Jr., da Silva AL, Gaspar AD, Scarpari DF, Alves JB, Girelli Neto R and de Oliveira TF: Evaluation of the cisplatin nephrotoxicity using the urinary neutrophil gelatinase-associated lipocalin (NGAL) in patients with head and neck cancer. J Bras Nefrol 36: 280-288, 2014.

17 Kanda Y: Investigation of the freely available easy-to-use software 'EZR' for medical statistics. Bone Marrow Transplant 48: 452-458, 2013.

18 Gaspari F, Cravedi P, Mandala M, Perico N, de Leon FR, Stucchi N, Ferrari S, Labianca R, Remuzzi G and Ruggenenti P: Predicting cisplatin-induced acute kidney injury by urinary neutrophil gelatinase-associated lipocalin excretion: a pilot prospective casecontrol study. Nephron Clin Pract 115: c154-160, 2010.

19 Klastersky J, Sculier JP, Lacroix H, Dabouis G, Bureau G, Libert P, Richez M, Ravez P, Vandermoten G and Thiriaux J: A randomized study comparing cisplatin or carboplatin with etoposide in patients with advanced non-small-cell lung cancer: European Organization for Research and Treatment of Cancer Protocol 07861. J Clin Oncol 8: 1556-1562, 1990.

20 Tiseo M, Martelli O, Mancuso A, Sormani MP, Bruzzi P, Di Salvia R, De Marinis F and Ardizzoni A: Short hydration regimen and nephrotoxicity of intermediate to high-dose cisplatin-based chemotherapy for outpatient treatment in lung cancer and mesothelioma. Tumori 93: 138-144, 2007.

21 Horinouchi H, Kubota K, Itani H, Taniyama TK, Nakamichi S, Wakui H, Kanda S, Nokihara H, Yamamoto N, Sekine I and Tamura T: Short hydration in chemotherapy containing cisplatin $\left(>/=75 \mathrm{mg} / \mathrm{m}^{2}\right)$ for patients with lung cancer: a prospective study. Jpn J Clin Oncol 43: 1105-1109, 2013.

22 Hotta K, Takigawa N, Hisamoto-Sato A, Ichihara E, Kudo K, Uchida K, Yanase-Nakamura K, Tanaka H, Kato Y, Tabata M, Tanimoto M and Kiura K: Reappraisal of short-term low-volume hydration in cisplatin-based chemotherapy: results of a prospective feasibility study in advanced lung cancer in the Okayama Lung Cancer Study Group Trial 1002. Jpn J Clin Oncol 43: 1115-1123, 2013. 